\title{
Effects of two hydroponic components on water quality, snakehead fish growth and leaf mustard production in aquaponic system
}

Tu P. C. Nguyen ${ }^{1 *}$, Ha N. Nguyen ${ }^{2,3}$, Thuy T. T. Thai ${ }^{3}$, Phong T. Tran ${ }^{3}, \&$ Tri N. Nguyen ${ }^{1}$

${ }^{1}$ Faculty of Fisheries, Nong Lam University, Ho Chi Minh City, Vietnam

${ }^{2}$ Research Institute for Biotechnology and Environment, Nong Lam University, Ho Chi Minh City, Vietnam

${ }^{3}$ Faculty of Biological Sciences, Nong Lam University, Ho Chi Minh City, Vietnam

ARTICLE INFO
Research Paper
Received: February 02, 2021
Revised: April 05, 2021
Accepted: April 15, 2021

Keywords

Aquaponics

Floating raft system

Leaf mustard

Media filled system

Snakehead fish

\section{${ }^{*}$ Corresponding author}

Nguyen Phuc Cam Tu

Email: npctu@hcmuaf.edu.vn

\begin{abstract}
Aquaponic model is a farming system that integrates a recirculating aquaculture system with hydroponics. There are three hydroponic methods commonly employed in the aquaponics systems: the media bed (MB), the nutrient film technique (NFT) and the deep-water culture - floating rafts (DWC). This study was conducted to evaluate effects of two hydroponic systems (DWC and MB) on water quality parameters, growth rate of fish and development of vegetable in the aquaponic model of snakehead fish (Channa striata) and leaf mustard (Brassica juncea). Snakehead fish were stocked with a density of 40 fish/75 liters of water and were cultured for 167 days. The results showed that daily temperature, $\mathrm{pH}$ and dissolved oxygen parameters in the two systems were almost the same and relatively stable while the electrical conductivity in the MB was much higher than that in the DWC. Similarly, the levels of the parameters weekly monitored (ammonia, nitrite, nitrate, total phosphorus, and alkalinity) in the MB were higher than those in the DWC. At the end of the experiment, final weight, weight gain, specific growth rate and survival rate of fish in the MB treatment were higher than those in the DWC treatment, but the feed conversion rate of fish in the MB was lower than that in the DWC. On the contrary, vegetable yields in the DWC were significantly higher than those in the MB. In general, the DWC aquaponics work better than the MB system.
\end{abstract}

Cited as: Nguyen, T. P. C, Nguyen, H. N, Thai, T. T. T., Tran, P. T, \& Nguyen, T. N. (2021). Effects of two hydroponic components on water quality, snakehead fish growth and leaf mustard production in aquaponic system. The Journal of Agriculture and Development 20(2), 27-35. 


\title{
Ảnh hưởng của hai hệ thống thủy canh lên chất lượng nước và phát triển của cá lóc và cải xanh trong mô hình aquaponic
}

\author{
Nguyễn Phúc Cẩm Tú ${ }^{1 *}$, Nguyễn Ngọc Hà ${ }^{2,3}$, Thái Thị Thanh Thủy ${ }^{3}$, \\ Trần Triệu Phong ${ }^{3}$ \& Nguyễn Như Tri $i^{1}$ \\ ${ }^{1}$ Khoa Thủy Sản, Trường Đại Học Nông Lâm TP.HCM, TP. Hồ Chí Minh \\ ${ }^{2}$ Viện Nghiên Cứu Công Nghệ Sinh Học và Môi Trường, Trường Đại Học Nông Lâm TP.HCM, TP. Hồ Chí \\ Minh \\ ${ }^{3}$ Khoa Khoa Học Sinh Học, Trường Đại Học Nông Lâm TP.HCM, TP. Hồ Chí Minh
}

\section{THÔNG TIN BÀI BÁO}

Bài báo khoa học

Ngày nhận: 02/02/2021

Ngày chỉnh sửa: 05/04/2021

Ngày chấp nhận: 15/04/2021

Từ khóa

Aquaponic

Cá lóc đen

Cải be xanh

Hệ thống bè nổi

Hệ thống giá thể sỏi

*Tác giả liên hệ

Nguyễn Phúc Cẩm Tú

Email: npctu@hcmuaf.edu.vn

\section{TÓM TẮT}

Mô hình aquaponic là sự kết hợp giữa nuôi thủy sản tuần hoàn và trồng rau thủy canh. Mô hình aquaponic có ba phương pháp thủy canh được dùng phổ biến: sử dụng lớp giá thể (GTS), màng dinh dưỡng (NFT) và canh tác nước sâu - bè nổi (bè nổi - $\mathrm{BN}$ ). Nghiên cứu này được thực hiện nhằm đánh giá ảnh hưởng của hai hệ thống thủy canh $\mathrm{BN}$ và GTS lên các thông số chất lượng nước, tăng trưởng của cá và phát triển của cây trong mô hình aquaponic nuôi cá lóc đen (Channa striata) kết hợp với trồng cải xanh (Brassica juncea). Cá lóc được thả nuôi với mật độ 40 con/75 lít nước và tiến hành nuôi trong 167 ngày. Kết quả cho thấy các chỉ tiêu theo dõi hằng ngày như nhiệt độ, $\mathrm{pH}$ và ôxy hòa tan ở hai hệ thống như nhau và tương đối ổn định; trong khi chỉ tiêu EC ở nghiệm thức GTS cao hơn so với hệ thống BN. Tương tự, hàm lượng của các thông số theo dõi hàng tuần (amôn, nitrít, nitrát, phốtpho tổng và độ kiềm) ở nghiệm thức GTS cao hơn so với nghiệm thức BN. Trọng lượng trung bình của cá lóc cuối thí nghiệm, tăng trưởng tuyệt đối và tương đối và tỷ lệ sống ở hệ thống GTS cao hơn, nhưng FCR thấp hơn so với hệ thống BN. Trái lại, năng suất rau thu hoạch ở hệ thống BN cao hơn rất đáng kể so với hệ thống GTS. Nhìn chung, mô hình aquaponic BN có hiệu quả cao hơn mô hình aquaponic GTS.

\section{1. Đặt Vấn Đề}

Aquaponic là sự kết hợp của nuôi thủy sản (aquaculture) và thủy canh (hydroponics, trồng cây không cần đất). Trong hệ thống aquaponic, nước thải giàu dinh dưỡng từ bể cá được sử dụng để trồng cây thủy canh, điều này là tốt cho cá vì rễ cây và hệ vi sinh vật sẽ giúp loại bỏ chất độc trong nước như $\mathrm{NH}_{3}, \mathrm{NO}_{2}^{-}, \ldots$ Cây và vi sinh vật có vai trò như một bộ lọc sinh học, làm giảm amôn, nitrít, nitrát, phốtpho; kết quả là nước sau khi lọc sẽ được tái tuần hoàn trở lại bể cá (McMurtry \& ctv., 1997; Somerville \& ctv., 2014).

Một mô hình aquaponic thường gồm có bể nuôi cá, tách cặn, lọc sinh học, hệ thống thủy canh và bơm. Ở hệ thống canh tác nước sâu - bè nổi, cây được trồng trên bè xốp nổi. Rễ cây được thả tự do trong nước, nơi xảy ra quá trình hấp thu chất dinh dưỡng. Hệ thống bè nổi có mực nước bên phía dưới bè sâu từ 25 đến $50 \mathrm{~cm}$, nên lượng nước sử dụng trong hệ thống này nhiều hơn gấp bốn lần so với các hệ thống khác (Rakocy \& ctv., 2006; Rakocy, 2012). Trong hệ thống tưới ngập xả cạn - giá thể sỏi, rễ của cây trồng và giá thể trơ có tác dụng loại bỏ các chất thải rắn từ bể cá, với hệ thống này không cần lắp đặt thêm bể lắng và lọc sinh học. Bùn và chất thải rắn từ bể cá bị giữ lại trong các giá thể trồng cây và được quần thể vi sinh vật phân giải. (Rakocy \& ctv., 2006).

Cá lóc là loại thực phẩm có giá trị dinh dưỡng cao, thơm ngon. Nghề nuôi cá lóc đã đem lại hiệu quả kinh tế cao cho các hộ nông dân ở các tỉnh đồng bằng sông Cửu Long. Tuy nhiên, sự ô nhiễm 
môi trường ao nuôi/vùng nuôi, sự bùng phát dịch bệnh do vi khuẩn, lạm dụng kháng sinh,... đã hạn chế sự phát triển nghề nuôi cá lóc thâm canh (Cao \& ctv., 2014). Trong đó, vấn đề xử lý nước thải/tuần hoàn tái sử dụng nước cho các mô hình nuôi cá lóc là vấn đề nan giải cho người nuôi. Cá lóc cần nhu cầu protein rất cao cho tăng trưởng và trao đổi chất (Tran \& ctv., 2005). Nhưng phần lớn thức ăn không được sử dụng hoặc được bài tiết dưới dạng các hợp chất nitơ độc (amôn, nitrít) gây phú dưỡng hệ sinh thái nước. Trong quá trình nuôi, để đảm bảo môi trường nước tốt cho cá tăng trưởng, người nuôi phải thay nước thường xuyên (Lam \& ctv., 2011).

Do đó, nghiên cứu này được thực hiện nhằm đánh giá ảnh hưởng của hai hệ thủy canh (bè nổi và giá thể sỏi) lên các thông số chất lượng nước, tăng trưởng của cá và phát triển của rau trong mô hình aquaponic nuôi cá lóc kết hợp trồng cải xanh qui mô hộ gia đình.

\section{Vật Liệu và Phương Pháp Nghiên Cứu}

\subsection{Vật liệu}

Nghiên cứu này được tiến hành ở khu thí nghiệm của Viện Nghiên cứu Công nghệ Sinh học và Môi trường (RIBE), Trường Đại học Nông Lâm TP.HCM. Cá lóc giống được mua ở Trại cá giống Mười Thanh, TP. Biên Hòa, tỉnh Đồng Nai. Cá được nuôi trong bể composite $1 \mathrm{~m}^{3}$ để thích nghi với điều kiện thí nghiệm trong một tuần và được cho ăn thức ăn viên thương mại hai lần/ngày ( 7 giờ và 17 giờ), với lượng ăn thỏa mãn nhu cầu. Khi cá đạt trọng lượng khoảng 9,5 - 10,5 g/con thì tiến hành bố trí thí nghiệm. Cá có trọng lượng trung bình $10,1 \pm 0,4 \mathrm{~g} /$ con được thả vào bể với mật độ 40 con/75 L nước nuôi dựa trên kết quả nghiên cứu của Cao \& ctv. (2014) và Phan \& Cao (2014).

\subsection{Hệ thống thí nghiệm và vận hành}

Thí nghiệm được bố trí với hai nghiệm thức là hai hệ thống thủy canh: hệ thống canh tác nước sâu - bè nổi $(\mathrm{BN})$ và hệ thống tưới ngập xả cạn giá thể sỏi (GTS), mỗi nghiệm thức lặp lại 3 lần. Toàn bộ hệ thống thí nghiệm được đặt trong nhà lưới.

Hệ thống BN được thiết kế dựa theo tỷ lệ lượng thức ăn/diện tích trồng cây là $60 \mathrm{~g} / \mathrm{m}^{2}$ (Rakocy \& ctv., 2006). Sinh khối cá dự kiến đạt $12 \mathrm{~kg} /$ bể với tỷ lệ cho ăn $3 \%$ trọng lượng thân, lượng ăn tối đa là $360 \mathrm{~g} /$ ngày. Hệ thống BN gồm có bể cá, bể lọc cặn, bể lọc sinh học và bể trồng rau. Bể cá là thùng nhựa hình chữ nhật có thể tích $100 \mathrm{~L}$ (kích thước dài $\mathrm{x}$ rộng $\mathrm{x}$ chiều cao bể là $610 \mathrm{~mm} \mathrm{x} 420$ mm x $390 \mathrm{~mm}$ ), được đặt chìm dưới đất khoảng $20 \mathrm{~cm}$. Thể tích nước trong bể được duy trì ở mức $75 \mathrm{~L}$. Bể lọc cặn và bể lọc sinh học là thùng nhựa hình trụ (đường kính $30 \mathrm{~cm}$, cao $54 \mathrm{~cm}$ ) có thể tích khoảng $35 \mathrm{~L}$, được nối thông với nhau bằng ống nhựa $\Phi 42$. Bể lọc cặn được thiết kế kiểu tự lắng. Bể lọc sinh học được thiết kế theo kiểu giá thể lơ lửng sử dụng $15 \mathrm{~L}$ hạt nhựa Kaldnes. Bể trồng rau làm bằng composite hình chữ nhật với kích thước dài x rộng $\mathrm{x}$ cao tương ứng là $3 \mathrm{~m} \mathrm{x}$ $2 \mathrm{~m}$ x $0,3 \mathrm{~m}$, thể tích $1800 \mathrm{~L}$ (chứa $1300 \mathrm{~L}$ nước) được đặt nằm trên mặt đất. Bè nổi là các tấm xốp XPS, mỗi tấm xốp có kích thước 0,6 x 1,2 m (dày $5 \mathrm{~cm}$ ) được khoét 24 lỗ/tấm (tổng cộng 6 tấm) và ở đầu mỗi bể, có thêm 3 tấm xốp kích thước 0,6 $\mathrm{m} \times \mathrm{x} 0,4 \mathrm{~m}$ được khoét 9 lỗ/tấm. Lỗ khoét tròn có đường kính $5 \mathrm{~cm}$, khoảng cách giữa hai lỗ (tâm cách tâm) trên một hàng ngang là $20 \mathrm{~cm}$ và trên mỗi hàng dọc là $15 \mathrm{~cm}$. Tổng cộng có 171 cây/hệ thống bè nổi (mật độ 30 cây $/ \mathrm{m}^{2}$ ) (Hình 1 ). Trong bể cá, bể lọc sinh học và bể rau sử dụng hệ thống sục khí liên tục để tạo sự khuấy trộn nước, tăng lượng ôxy cho cá và vi khuẩn. Nước từ bể cá được bơm vào bể lọc cặn, tự chảy qua bể lọc sinh học đến bể trồng rau và tuần hoàn trở lại bể cá. Lưu lượng nước chảy trong toàn bộ hệ thống là 360 L/giờ.

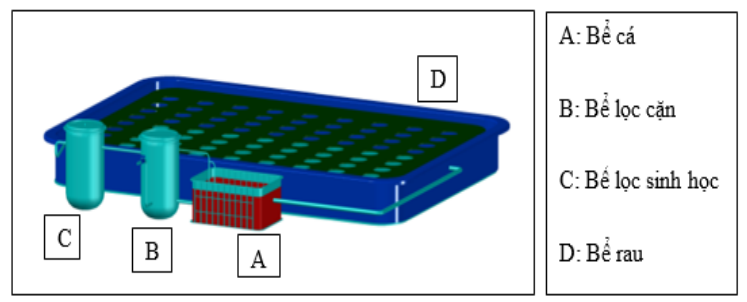

Hình 1. Hệ thống canh tác nước sâu - bè nổi.

Hệ thống GTS được thiết kế theo hướng dẫn của Timmons \& Ebeling (2010): chọn tỷ lệ 1 thể tích cá nuôi/2 thể tích giá thể sỏi. Hệ thống GTS gồm có bể cá, bể rau và bể hồi nước. Bể cá và bể hồi là bể nhựa hình chữ nhật với thể tích $100 \mathrm{~L}$ (kích thước dài $\mathrm{x}$ rộng $\mathrm{x}$ chiều cao bể là $610 \mathrm{~mm}$ x $420 \mathrm{~mm}$ x $390 \mathrm{~mm}$ ). Bể cá được đặt trên kệ cách mặt đất $60 \mathrm{~cm}$ được sục khí liên tục, trong khi đó bể hồi được đặt trên mặt đất. Bể rau được làm bằng composite có kích thước dài $\mathrm{x}$ rộng $\mathrm{x}$ cao tương ứng là $1,2 \mathrm{~m} \mathrm{x} 1 \mathrm{~m}$ x $0,2 \mathrm{~m}$ (thể tích 
240 L) được đặt trên kệ cao cách mặt đất khoảng $40 \mathrm{~cm}$ (Hình 2). Trong bể rau cho các hạt sét nung cao lên khoảng $15 \mathrm{~cm}$ (khoảng $180 \mathrm{~L}$ hạt sét nung) và có lắp một bell-siphon để tự động rút nước ở đáy và chảy về bể hồi. Máy bơm sẽ bơm nước ngược từ bể hồi lên bể cá và chảy sang bể rau. Ở hệ thống này, một chu kỳ bơm và xả cạn là 16 phút. Mỗi hệ thống GTS có tổng cộng 50 rọ trồng cây (mật độ khoảng 42 cây $/ \mathrm{m}^{2}$ ).

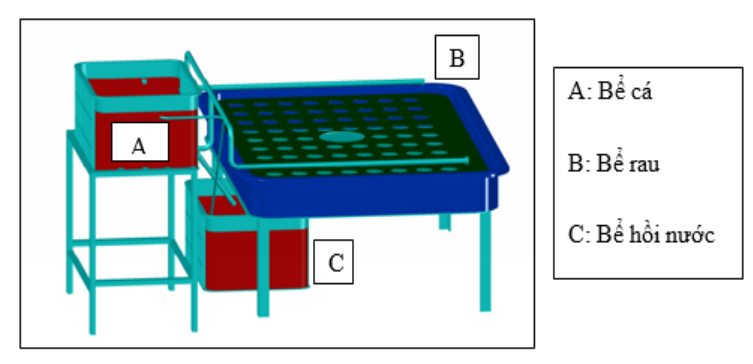

Hình 2. Hệ thống tưới ngập xả cạn - giá thể sỏi.

Thời gian thí nghiệm kéo dài 167 ngày (từ ngày $7 / 8 / 2020$ đến 21/1/2021). Thức ăn thí nghiệm là thức ăn dành cho cá lóc của Công ty TNHH Khoa Kỹ Sinh vật Thăng Long (cỡ viên 2 - 6 mm, độ đạm 42 - 44\%). Cá lóc được cho ăn hai lần trong ngày ( 7 giờ và 17 giờ), với lượng ăn thỏa mãn nhu cầu, mỗi lần cho ăn kéo dài khoảng 1 giờ. Sau khi cá ngừng ăn, tiến hành thu và ghi nhận lượng thức ăn thừa để tính lượng ăn. Thức ăn cho ăn được bổ sung thêm vitamin $\mathrm{C}$ (với liều $0,5 \%$ ) bằng cách hòa tan vitamin $\mathrm{C}$ vào nước và phun lên viên thức ăn.

Hạt giống rau được ngâm và đem ủ trong khăn ẩm từ 10 - 12 giờ. Sau đó, hạt giống được gieo vào xốp ươm (94 lỗ/tấm). Sau khi hạt nảy mầm được 10 - 12 ngày, cây có 1 - 2 lá thật, bắt đầu chuyển cây vào hệ thống, sau 30 ngày tiến hành thu hoạch rau. Trong thời gian thí nghiệm, có tổng cộng ba đợt trồng và thu hoạch rau.

\subsection{Lấy và phân tích mẫu nước}

Nhiệt độ, $\mathrm{pH}$, ôxy hòa tan $(\mathrm{DO})$ và độ dẫn điện $(\mathrm{EC})$ được đo hằng ngày vào hai thời điểm ( 7 giờ và 14 giờ) lần lượt bằng máy đo Digital thermometer WT - 1, Denver pH meter UP- 10, Milwwaukee MW 600 Dissolved Oxygen và Conductivity Meter B - 173. Tổng nitơ amôn (TAN), nitrít, nitrát, phốtpho tổng số $(\mathrm{TP})$ và độ kiềm được đo một tuần một lần (ngày thứ hai hàng tuần) tại hai vị trí/hệ thống: bể cá và đầu ra của bể rau. Tất cả các chỉ tiêu được phân tích theo các phương pháp chuẩn của Baird \& ctv. (2017). Tổng nitơ amôn (TAN), nitrít, nitrát, phốtpho tổng số $(\mathrm{TP})$ và độ kiềm được xác định tương ứng bằng phương pháp phenate $\left(4500-\mathrm{NH}_{3} \mathrm{~F}\right)$, phương pháp trắc quang $\left(4500-\mathrm{NO}_{2}^{-} \mathrm{B}\right)$, phương pháp khử cadimi $\left(4500-\mathrm{NO}_{3}^{-} \mathrm{E}\right)$, phương pháp axít ascorbic (4500-P E) và phương pháp chuẩn độ (2320 B).

\section{4. Đánh giá tăng trưởng của cá và sinh trưởng của rau}

Các công thức tính toán như sau:

Tăng trưởng tuyệt đối:

$$
\mathrm{WG}(\mathrm{g} / \mathrm{con})=\mathrm{W}_{\mathrm{t}}-\mathrm{W}_{\mathrm{o}}
$$

Tăng trưởng tương đối:

$$
\operatorname{SGR}(\% / \text { ngày })=\frac{\ln \mathrm{W}_{\mathrm{t}}-\ln \mathrm{W}_{\mathrm{o}}}{\mathrm{t}} \times 100 \%
$$

Trong đó:

$\mathrm{W}_{\mathrm{o}}$ : Khối lượng cá trước, $\mathrm{g} / \mathrm{con}$;

$\mathrm{W}_{\mathrm{t}}$ : Khối lượng cá sau, g/con;

t: Thời gian giữa hai lần thu mẫu, ngày.

Hệ số chuyển đổi thức ăn (FCR):

$$
\mathrm{FCR}=\frac{\mathrm{F}}{\mathrm{M}_{\mathrm{t}}-\mathrm{M}_{\mathrm{o}}+\mathrm{M}_{\mathrm{c}}}
$$

Trong đó:

F: lượng thức ăn đã cung cấp cho cá ăn giữa hai lần thu mẫu, g;

$\mathrm{M}_{\mathrm{o}}$ : Tổng khối lượng cá trước, g;

$\mathrm{M}_{\mathrm{t}}$ : Tổng khối lượng cá sau, g;

$\mathrm{M}_{\mathrm{c}}$ : Tổng khối lượng cá chết, $\mathrm{g}$.

Tỉ lệ sống:

Tỷ lệ sống $(\%)=\frac{\text { số lượng cá ở thời điểm } \mathrm{t}}{\text { số lượng cá ở thời điểm o }} \times 100 \%$

Đánh giá sự sinh trưởng của rau:

Năng suất cá thể (g/cây): Khối lượng trung bình của các cây theo dõi khi thu hoạch (20 cây/bể trồng rau).

Năng suất lý thuyết (g/hệ): Khối lượng trung bình của cây theo dõi $x$ số cây/hệ.

Năng suất thực thu (g/hệ): Cân khối lượng thực tế của tất cả các cây trong ô thí nghiệm khi thu hoạch.

\subsection{Phân tích thống kê}

Các phân tích thống kê thực hiện theo hướng dẫn của Gomez và Gomez (1984) và Bhujel 
Bảng 1. Giá trị của các chỉ tiêu đo hàng ngày trong các bể nuôi cá lóc ở hai nghiệm thức

\begin{tabular}{lccccc}
\hline \multirow{2}{*}{ Chỉ tiêu } & \multicolumn{2}{c}{ Giá thể sỏi } & \multicolumn{2}{c}{ Bè nổi } & Giá trị \\
\cline { 2 - 5 } & Sáng & Chiều & Sáng & Chiều & xác suất \\
\hline Nhiệt độ $\left({ }^{\circ} \mathrm{C}\right)$ & $26,9 \pm 1,2$ & $29,4 \pm 1,1$ & $27,8 \pm 1,2$ & $29,3 \pm 1,0$ & $>0,05$ \\
pH & $7,49 \pm 0,32$ & $7,46 \pm 0,37$ & $6,80 \pm 0,37$ & $6,81 \pm 0,33$ & $<0,001$ \\
Ôxy hòa tan $(\mathrm{mg} / \mathrm{L})$ & $6,57 \pm 0,39$ & $6,54 \pm 0,36$ & $6,70 \pm 0,43$ & $6,69 \pm 0,46$ & $<0,001$ \\
Độ dẫn điện $(\mathrm{mS} / \mathrm{cm})$ & $1,37 \pm 0,27$ & $1,37 \pm 0,28$ & $0,532 \pm 0,165$ & $0,534 \pm 0,171$ & $<0,001$ \\
\hline
\end{tabular}

Giá trị thể hiện trong bảng là trung bình \pm độ lệch chuẩn. Giá trị xác suất là kết quả phân tích của kiểm định $\mathrm{T}$ hai mẫu độc lập dùng để so sánh các giá trị trung bình giữa hai nghiệm thức.

(2008). Sự khác biệt về giá trị trung bình của các chỉ tiêu đo hàng ngày (nhiệt độ, $\mathrm{pH}, \mathrm{DO}$ và $\mathrm{EC}$ ) giữa hai nghiệm thức được phân tích bằng kiểm định $\mathrm{T}$ hai mẫu độc lập. Với các chỉ tiêu chất lượng nước đo theo tuần, để đánh giá sự biến động giữa hai nghiệm thức theo thời gian thu mẫu, phân tích thống kê bằng phương sai một yếu tố với đo lường lặp lại (repeated measures ANOVA) với các nghiệm thức (bể thủy canh) là yếu tố thí nghiệm và đợt thu mẫu là yếu tố đo lường lặp lại. Kiểm định Bonferroni được dùng để so sánh sự khác biệt giữa các đợt thu mẫu. Trong cùng một nghiệm thức, để so sánh sự khác biệt của các chỉ tiêu chất lượng nước giữa bể cá và bể rau sử dụng kiểm định $\mathrm{T}$ hai mẫu liên hệ. So sánh sự khác biệt giữa hai nghiệm thức về giá trị trung bình của các chỉ tiêu tăng trưởng (khối lượng ban đầu/cuối, WG, SGR), tỷ lệ sống và $\mathrm{FCR}$ của cá và chiều dài rễ và các chỉ tiêu năng suất (cá thể, lý thuyết và thực thu) của rau sử dụng kiểm định T hai mẫu độc lập.

Số liệu được biểu diễn dưới dạng giá trị trung bình \pm độ lệch chuẩn. Mức xác suất $P<0,05$ được chấp nhận như tiêu chuẩn đánh giá sự khác biệt có ý nghĩa thống kê. Tất cả các phân tích thống kê được thực hiện bằng phần mềm IBM SPSS Statistics for Windows, Version 19.0 (Armonk, NY: IBM Corp).

\section{Kết Quả và Thảo Luận}

\subsection{Chất lượng nước}

\subsubsection{Các chỉ tiêu đo hàng ngày}

Nhìn chung, có sự chênh lệch về nhiệt độ giữa buổi sáng và buổi chiều: ở mỗi hệ thống nhiệt độ vào buổi chiều thường cao hơn buổi sáng (Bảng 1). Nhiệt độ ở hệ thống BN ổn định hơn so với hệ thống GTS. Điều này có thể là do sự khác nhau trong thiết kế hệ thống: (i) ở hệ thống BN bể cá được đặt âm dưới đất, và (ii) thể tích nước ở hệ thống BN nhiều gấp 10 lần hệ thống GTS. Nhiệt độ không chỉ ảnh hưởng đến loài cá nuôi, mà còn ảnh hưởng đến sự phát triển của thực vật và hiệu quả của hệ thống lọc sinh học. Theo Ngo (2003), nhiệt độ thích hợp nuôi cá lóc là $20-30^{\circ} \mathrm{C}$. Trong khi cải xanh có thể thích nghi với khoảng nhiệt dộ rộng từ $10-27^{\circ} \mathrm{C}$ và hệ lọc sinh học hoạt động tốt nhất ở nhiệt độ trong khoảng $25-30^{\circ} \mathrm{C}$ (Somerville \& ctv., 2014; Sallenave, 2016).

Giá trị pH của hệ thống GTS luôn cao hơn so với hệ thống BN (Bảng 1). Nguyên nhân có thể là do hệ thống GTS dùng các hạt đất sét nung có khả năng đệm giúp giữ giá trị $\mathrm{pH}$ luôn cao hơn. Giá trị pH là một trong những thông số chất lượng nước quan trọng trong hệ thống aquaponic, có ảnh hưởng rất lớn đến tất cả các thành phần, đặc biệt là thực vật và vi khuẩn. Giá trị $\mathrm{pH}$ có ảnh hưởng đến chất dinh dưỡng sẵn có cho cây: ở khoảng pH 6,0 - 6,5 tất cả các chất dinh dưỡng đa - vi lượng đều ở dạng sẵn có cho cây, ngoài khoảng pH này cây rất khó hấp thu chất dinh dưỡng, đặc biệt là $\mathrm{Fe}, \mathrm{Ca}$ và $\mathrm{Mg}$. Trái lại, vi khuẩn nitrát hóa hoạt động tối ưu ở $\mathrm{pH}>7,5$ và $\mathrm{khi} \mathrm{pH}<6,0$ vi khuẩn ngưng hoạt động. Do đó, để duy trì hoạt động tối ưu của cả ba thành phần cá - rau - vi khuẩn, giá trị $\mathrm{pH}$ nên nằm trong khoảng $6,8-7,0$ (Somerville \& ctv., 2014; Sallenave, 2016). Trong hai hệ thống, giá trị $\mathrm{pH}$ của hệ thống $\mathrm{BN}$ thích hợp cho mô hình aquaponic hơn.

Hàm lượng DO ở cả hai hệ thống BN và GTS luôn được duy trì tương đối ổn định ở mức (> $5 \mathrm{mg} / \mathrm{L})$ đảm bảo cho cá và hệ vi khuẩn nitrát hóa hoạt động bình thường (Bảng 1). Trong hệ thống aquaponic, hàm lượng $\mathrm{DO}$ tối ưu nằm trong khoảng $4-8 \mathrm{mg} / \mathrm{L}$ (Somerville \& ctv., 2014; Sallenave, 2016).

Theo Bảng 1, EC buổi sáng và buổi chiều trong cùng hệ thống ở cả hai nghiệm thức gần như tương đồng với nhau. Độ dẫn điện trong hệ thống aquaponic nằm trong khoảng $0,3-1,1 \mathrm{mS} / \mathrm{cm}$ là phù hợp cho cá và rau (Wortman, 2015). Do đó, 
EC trong nghiên cứu này tương tự với các nghiên cứu khác.

\subsubsection{Các chỉ tiêu đo theo tuần}

Hàm lượng TAN ở đầu ra của bể rau ở hai hệ thống đều thấp hơn so với bể cá và có khác biệt có ý nghĩa về mặt thống kê $(P<0,05)$. Điều này có lẽ là nhờ hoạt động của các vi khuẩn nitrát giúp chuyển hóa amôn (Bảng 2). Ngoài ra, hàm lượng TAN trong nước ở hai nghiệm thức có sự khác biệt có ý nghĩa về mặt thống kê ở cả bể cá và đầu ra của bể rau: hàm lượng TAN ở hệ thống GTS cao hơn $\mathrm{BN}(P<0,05)$. Hàm lượng TAN trung bình ở bể cá và ở đầu ra bể rau của GTS cao hơn tương ứng là 5,5 và 8,6 lần so với bể cá và đầu ra bể rau của $\mathrm{BN}$ (Bảng 2 ). Ở giai đoạn đầu của thí nghiệm, hàm lượng TAN ở bể cá của nghiệm thức GTS tương đối thấp và có xu hướng tăng dần và đạt giá trị cao ở tháng cuối của thí nghiệm. Nguyên nhân là do lượng thức ăn và sinh khối của cá tăng, dẫn đến việc tăng bài tiết TAN và hệ vi sinh trong hệ thủy canh GTS không có khả năng chuyển hóa hết lượng TAN này thành nitrít và nitrát. Ngược lại, hàm lượng TAN ở nghiệm thức BN luôn duy trì ở mức $<1 \mathrm{mg} / \mathrm{L}$, đặc biệt là ở bể trồng rau. Trong hệ thống aquaponic, hàm lượng TAN nên duy trì $<1 \mathrm{mg} / \mathrm{L}$ (Somerville và ctv., 2014; Sallenave, 2016). Các nghiên cứu nuôi cá lóc trong hệ thống tuần hoàn và bể bạt cho thấy cá lóc có thể sống trong môi trường có hàm lượng TAN khoảng 5 mg/L (Lam \& ctv., 2011; Cao \& ctv., 2014; Phan \& Cao, 2014).

Hàm lượng nitrit trung bình ở bể cá của mỗi hệ thống cao hơn có ý nghĩa thống kê so với mẫu ở đầu ra bể rau $(P<0,05)$, do có sự chuyển hóa nitrít thành nitrát để cây có thể hấp thụ và phát triển. Ngoài ra, sự khác biệt về hàm lượng nitrít trung bình giữa hai nghiệm thức có ý nghĩa về mặt thống kê $(P<0,05)$. Hàm lượng nitrít trung bình ở bể cá và bể rau của GTS cao hơn so với BN (Bảng 2). Hàm lượng nitrít ở hệ thống BN biến động tương đối ổn định hơn so với GTS. Hàm lượng nitrít trong hai hệ thống luôn nằm trong giới hạn phù hợp cho hoạt động hệ thống aquaponic $(<1 \mathrm{mg} / \mathrm{L})$ (Somerville \& ctv., 2014; Sallenave, 2016).

Hàm lượng nitrát trung bình ở bể cá và đầu ra của bể rau trong cùng hệ thống không có khác biệt, gần như là bằng nhau. Hàm lượng nitrát trung bình ở hệ thống GTS cao hơn BN (Bảng 2).

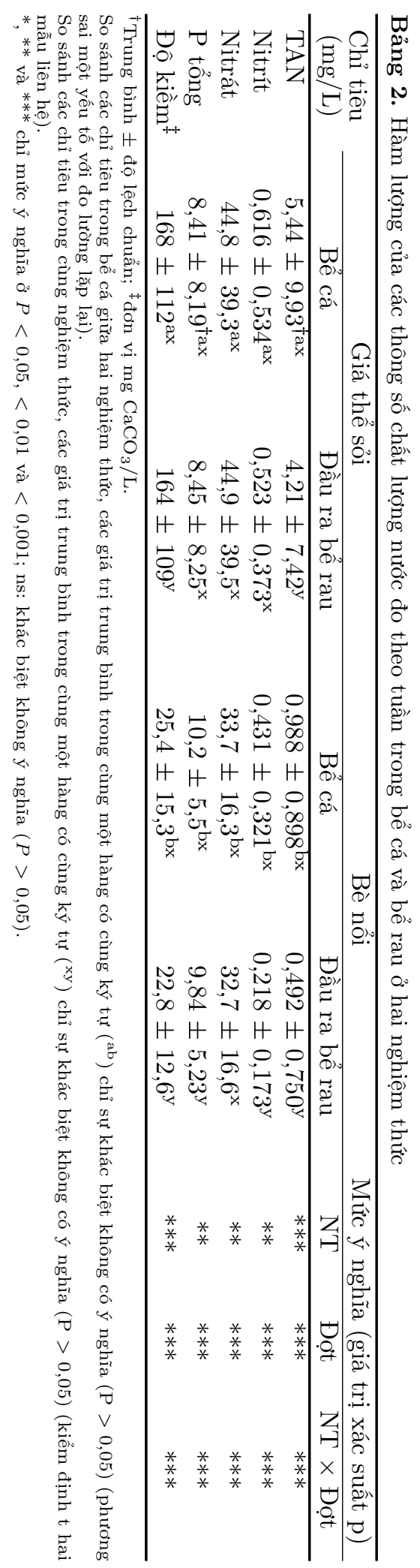


Hàm lượng nitrát ở hệ thống GTS cao hơn so với hệ thống $\mathrm{BN}$ ở giai đoạn đầu thí nghiệm, sau đó có xu hướng giảm dần và thấp hơn hệ thống $\mathrm{BN}$ ở giai đoạn cuối thí nghiệm. Theo Somerville \& ctv. (2014) và Sallenave (2016), hàm lượng nitrát trong hệ thống aquaponic nằm trong khoảng 5 - $150 \mathrm{mg} / \mathrm{L}$, chứng tỏ hệ thống hoạt dộng tốt (Somerville \& ctv., 2014).

Phốtpho $(\mathrm{P})$ là một trong những chất dinh dưỡng cần thiết cho sự phát triển của cây rau. Hàm lượng $\mathrm{P}$ tổng trung bình ở bể cá và đầu ra của bể rau ở mỗi hệ thống có sự khác biệt (Bảng 2). Hàm lượng $\mathrm{P}$ tổng trung bình ở hệ thống GTS khác biệt không có ý nghĩa thống kê giữa bể cá và đầu ra của bể rau. Nhưng ở hệ thống $B N$, hàm lượng $\mathrm{P}$ trung bình ở bể cá cao hơn có ý nghĩa thống kê so với đầu ra bể rau $(P<0,05)$. Khi so sánh giữa hai nghiệm thức, hàm lượng $\mathrm{P}$ tổng ở hệ thống BN cao hơn so với hệ thống GTS $(P<0,05)$; có lẽ là do lượng thức ăn thừa và phân cá được lưu giữ trong các GTS sỏi. Kết quả của nghiên cứu này cũng tương tự các nghiên cứu khác: hàm lượng $\mathrm{P}$ trong hệ thống aquaponic dao động trong khoảng 1 - 17 mg/L (Goddek \& ctv., 2015).

Độ kiềm trung bình ở hệ thống GTS cao hơn có ý nghĩa so với hệ thống $\mathrm{BN}(P<0,05)$. Khi bắt đầu thí nghiệm, độ kiềm ở hai hệ thống là như nhau và có xu hướng tăng dần theo thời gian nuôii, tăng nhanh ở giai đoạn cuối do việc bổ sung vôi $\mathrm{CaCO}_{3}$. Độ kiềm ở hệ thống $\mathrm{BN}$ luôn ở mức thấp hơn ngưỡng phù hợp trong mô hình aquaponic ( $\geq 100 \mathrm{mg} \mathrm{CaCO} 3 / \mathrm{L})$, trong khi đó độ kiềm ở hệ thống GTS luôn cao hơn ngưỡng này. Nguyên nhân có thể là do trong hệ thống $\mathrm{BN}$ quá trình nitrát hóa diễn ra mạnh mẻ, $\mathrm{H}^{+}$phóng thích ra từ quá trình này làm tiêu hao độ kiềm. Ngược lại, ở hệ thống GTS, quá trình nitrát diễn ra chậm hơn và đặc biệt phản ứng phản nitrát xảy ra trong GTS sỏi làm tăng độ kiềm (Somerville \& ctv., 2014; Sallenave, 2016).

\subsection{Tăng trưởng, tỷ lệ sống và hệ số chuyển đổi thức ăn của cá}

Trọng lượng trung bình cá ban đầu ở hai nghiệm thức không có sự khác biệt $(P>0,05)$. Trọng lượng trung bình của cá lóc cuối thí nghiệm và WG ở nghiệm thức GTS cao hơn có ý nghĩa thống kê so với nghiệm thức $\mathrm{BN}(P<0,05)$, nhưng sự khác biệt về SGR giữa hai nghiệm thức không có ý nghĩa thống kê $(P>0,05)$ (Bảng 3). Kết quả của nghiên cứu này cho thâyy tăng trưởng của cá lóc trong hệ thống aquaponic thấp hơn kết quả của các tác giả khác. Theo Cao \& ctv. (2014) và Phan \& Cao (2014), cá lóc có thể tăng trưởng từ cá giống $6,6-6,8 \mathrm{~g} / \mathrm{con}$ đến trọng lượng khoảng 345 - $380 \mathrm{~g} /$ con trong 110 - 120 ngày. Nguyên nhân có lẽ do nước trong hệ thống quá trong, khi cho cá ăn, cá nhát ăn; đặc biệt ở hệ thống $\mathrm{BN}$, do bể cá được đặt dưới đất, nên khi đi lại cho ăn, cá không ăn nhiều. Trong các nghiên cứu tiếp theo, cần che tối bể cá, nhất là khi cho cá ăn.

Sự khác biệt về tỷ lệ sống của cá lóc giữa nghiệm thức GTS và nghiệm thức $\mathrm{BN}$ không có ý nghĩa thống kê $(P>0,05)$ (Bảng 3 ). So với kết quả của các tác giả khác, tỷ lệ sống trung bình của cá lóc trong nghiên cứu này thấp hơn của các tác giả khác (Cao \& ctv., 2014; Phan \& Cao, 2014). Nghiệm thức GTS có FCR thấp hơn so với nghiệm thức $\mathrm{BN}(P<0,05)$ (Bảng 3$)$. So với kết quả của các tác giả khác, FCR thu được trong nghiên cứu này rất cao so với của các tác giả khác (Cao \& ctv., 2014; Phan \& Cao, 2014): dao động từ 1,05 - 1,13.

\subsection{Sinh trưởng của rau}

Năng suất cá thể ở nghiệm thức BN cao hơn so với nghiệm thức GTS (Bảng 4). Do đó, năng suất rau cải ở nghiệm thức $\mathrm{BN}$ cao hơn nghiệm thức GTS $(P<0,05)$. Ở đợt trồng rau 1 , năng suất rau thực thu ở nghiệm thức BN (4.205 \pm $2.224 \mathrm{~g} / \mathrm{hệ})$ cao gấp hơn 5,5 lần ở nghiệm thức GTS $(758 \pm 250 \mathrm{~g} / \mathrm{h}$ ệ). Ở đợt trồng rau 2, năng suất rau ở mỗi nghiệm thức tương đối thấp, GTS là $129 \pm 13 \mathrm{~g} / \mathrm{h}$ ẹ, ở BN là $769 \pm 324 \mathrm{~g} /$ hệ. Ở đợt trồng rau 3, năng suất rau thu được ở nghiệm thức GTS là $605 \pm 71 \mathrm{~g} /$ hệ, ở nghiệm thức $\mathrm{BN}$ là $7,117 \pm 1,325 \mathrm{~g} /$ hệ. Năng suất rau thu hoạch thấp ở hệ thống GTS cũng có thể là do hệ thủy canh GTS có tổng cộng 50 cây/hệ (mật độ khoảng 42 cây $/ \mathrm{m}^{2}$ ) thấp hơn so với hệ thống $\mathrm{BN}$ có tổng cộng 171 lỗ (mật độ 30 cây $/ \mathrm{m}^{2}$ ).

Trong 3 đợt trồng rau, đợt rau 3 cho năng suất cao nhất cả hai nghiệm thức. Ở đợt trồng rau 2 , cây phát triển không tốt do thời tiết ẩm, mưa liên tục nhiều ngày dẫn đến cây rau bị nhiễm nấm, xuất hiện sâu ăn lá, sâu đục thân. Ngoài ra, rệp xanh tấn công làm cho cây chậm phát triển, teo lá làm năng suất cây rau ở đợt 2 khi thu hoạch thấp. Thêm vào đó, ở nghiệm thức GTS, khi sinh khối cá tăng dẫn đến các vật chất hữu cơ tăng, các chất cặn tương đối nhiều làm quá trình phát 
Bảng 3. Ảnh hưởng của hai hệ thống thủy canh lên tăng trưởng, tỷ lệ sống và sử dụng thức ăn của cá lóc ở hai nghiệm thức

\begin{tabular}{lcc}
\hline Chỉ tiêu & Giá thể sỏi & Bể nổi \\
\hline Trọng lượng trung bình cá ban đầu $(\mathrm{g} / \mathrm{con})$ & $10,2 \pm 0,6^{\dagger \mathrm{a}}$ & $10,1 \pm 0,2^{\mathrm{a}}$ \\
Trọng lượng trung bình cá cuối thí nghiệm $(\mathrm{g} / \mathrm{con})$ & $208 \pm 13^{\mathrm{a}}$ & $171 \pm 7^{\mathrm{b}}$ \\
Tăng trưởng tuyệt đối $(\mathrm{g} / \mathrm{con})$ & $198 \pm 13^{\mathrm{a}}$ & $161 \pm 7^{\mathrm{b}}$ \\
Tăng trưởng tương đối $(\% /$ ngày) & $1,81 \pm 0,07^{\mathrm{a}}$ & $1,69 \pm 0,03^{\mathrm{a}}$ \\
Tỷ lệ sống (\%) & $90,8 \pm 1,4^{\mathrm{a}}$ & $87,5 \pm 6,6^{\mathrm{a}}$ \\
Hệ số chuyển đổi thức ăn & $1,54 \pm 0,12^{\mathrm{a}}$ & $1,90 \pm 0,06^{\mathrm{b}}$ \\
\hline
\end{tabular}

${ }^{\dagger}$ Trung bình \pm độ lệch chuẩn. Các giá trị trung bình trong cùng một hàng có cùng ký tự chỉ sự khác biệt không có ý nghĩa $(\dot{P}>0,05)$ (kiểm định T hai mẫu độc lập).

Bảng 4. Ảnh hưởng của hai hệ thống thủy canh lên chiều dài rễ và năng suất rau ở các đợt thu hoạch

\begin{tabular}{ccccc}
\hline $\begin{array}{c}\text { Đợt thu } \\
\text { hoạch }\end{array}$ & Nghiệm thức ${ }^{1}$ & $\begin{array}{c}\text { Năng suất cá thể } \\
(\mathrm{g} / \text { cây })\end{array}$ & $\begin{array}{c}\text { Năng suất lý thuyết } \\
\left(\mathrm{kg} / \mathrm{m}^{2}\right)\end{array}$ & $\begin{array}{c}\text { Năng suất thực thu } \\
\left(\mathrm{kg} / \mathrm{m}^{2}\right)\end{array}$ \\
\hline \multirow{2}{*}{1} & GTS & $13,3 \pm 4,6^{\mathrm{a}}$ & $666 \pm 232^{\mathrm{a}}$ & $758 \pm 250^{\mathrm{a}}$ \\
& BN & $27,4 \pm 17,0^{\mathrm{b}}$ & $4.678 \pm 2.900^{\mathrm{b}}$ & $4.205 \pm 2.224^{\mathrm{b}}$ \\
2 & GTS & $3,3 \pm 0,3^{\mathrm{a}}$ & $165 \pm 16^{\mathrm{a}}$ & $129 \pm 13^{\mathrm{a}}$ \\
& BN & $6,9 \pm 2,5^{\mathrm{b}}$ & $1.181 \pm 434^{\mathrm{b}}$ & $769 \pm 324^{\mathrm{b}}$ \\
3 & GTS & $13,2 \pm 1,6^{\mathrm{a}}$ & $660 \pm 81^{\mathrm{a}}$ & $605 \pm 71^{\mathrm{a}}$ \\
\hline
\end{tabular}

Ở cùng đợt thu hoạch, các giá trị trung bình trong cùng một cột có cùng ký tự chỉ sự khác biệt không có ý nghĩa $(P>$ 0,05) (kiểm định t hai mẫu độc lập).

${ }^{1} \mathrm{BN}$ : Hệ thống canh tác nước sâu - bè nổi $(\mathrm{BN})$; GST: hệ thống tưới ngập xả cạn - giá thể sỏi.

triển của rễ cây giảm, cây không hấp thụ được các chất dinh dưỡng do đó không phát triển, xuất hiện hiện tượng vàng lá và chết dần.

\section{Kết Luận}

Các chỉ tiêu chất lượng nước đo hằng ngày: nhiệt độ, pH, độ dẫn điện, ôxy hòa tan, TDS ở hệ thống thủy canh $\mathrm{BN}$ ổn định hơn so với hệ thống thủy canh GTS. Về các chỉ tiêu chất lượng nước đo hàng tuần: TAN, nitrít, nitrát, nitơ tổng, phốtpho tổng và phốtpho hòa tan ở hệ thống thủy canh BN đều thấp hơn so với hệ thống thủy canh GTS. So với các nghiên cứu khác, tăng trưởng của cá lóc nuôi trong hệ thống aquaponic ở nghiên cứu này còn thấp, nhưng FCR lại cao hơn. Mô hình aquaponic BN có năng suất rau đạt hiệu quả cao hơn so với mô hình GTS ở ba đợt trồng rau. Do đó, mô hình aquaponic BN hiệu quả cao hơn mô hình aquaponic GTS.

\section{Lời Cam Đoan}

Các tác giả tuyên bố không có bất kỳ mâu thuẫn nào liên quan đến việc xuất bản bài báo này.

\section{Lời Cảm Ơn}

Tập thể tác giả xin chân thành cảm ơn Trường Đại Học Nông Lâm TP.HCM đã tài trợ kinh phí thực hiện (Mã số: CS-CB19-TS-01).

\section{Tài Liệu Tham Khảo (References)}

Baird, R. B., Eaton, A. D., \& Rice, E. W. (2017). Standard methods for the examination of water and wastewater (23 ${ }^{\text {rd }}$ ed.). Washington DC, USA: Water Environment Federation, American Public Health Association, American Water Works Association.

Bhujel, R. C. (2008). Statistics for aquacultureed. New Jersey, USA: Wiley-Blackwell.

Cao, V. T., Pham, T. L., \& Truong, Q. P. (2014). Effects of stocking density on water quality, growth and survival of snakehead fish (Channa striata) cultured in recirculating system. Can Tho University Journal of Science 2, 79-85.

Goddek, S., Delaide, B., Mankasingh, U., Ragnarsdottir, K. V., Jijakli, H., \& Thorarinsdottir, R. (2015). Challenges of sustainable and commercial aquaponics. Sustainability 7(4), 4199-4224.

Gomez, K. A., \& Gomez, A. A. (1984). Statistical procedures for agricultural research ( $2^{\text {nd }}$ ed.). New York, USA: John Wiley \& Sons.

Lam, M. L., Nguyen, T. H., \& Duong, N. L. (2011). Trials of snakehead (Channa sp.) culture in lined tanks in 
Hau Giang province. Proceedings of the $4^{\text {th }}$ Conference on Aquaculture and Fisheries. Can Tho City, Vietnam: Can Tho University.

McMurtry, M. R., Sanders, D. C., Cure, J. D., Hodson, R. G., Haning, B. C., \& Amand, E. C. S. (1997). Efficiency of water use of an integrated fish/vegetable co-culture system. Journal of the World Aquaculture Society 28(4), 420-428.

Ngo, T. L. (2003). Culture technique of eel, frog, softshell turtles and snakehead fish ( $9^{\text {th }}$ ed.). Ho Chi Minh City, Vietnam: Agricultural Publishing House.

Phan, T. T. V., \& Cao, V. T. (2014). An effect of feeding frequency on the growth of snakehead (Channa striata) reared in recirculation systems. An Giang University Journal of Science 4(3), 79-84.

Rakocy, J. E. (2012). Aquaponics - integrating fish and plant culture. In Tidwell, J. H. (Ed.). Aquaculture production systems. New York, USA: John Wiley \& Sons.

Rakocy, J. E., Masser, M. P., \& Losordo, T. M. (2006). Recirculating aquaculture tank production systems: Aquaponics integrating fish and plant culture. Retrieved November 1, 2006, from http://aquaculture.ca.uky.edu/publication/recirculati ng-aquaculture-tank-production-systems-aquaponicsintegrating-fish-and-plant.
Sallenave, R. (2016). Important water quality parameters in aquaponics systems. New Mexico, USA: College of Agricultural, Consumer and Environmental Sciences, New Mexico State University.

Somerville, C., Cohen, M., Pantanella, E., Stankus, A., \& Lovatelli, A. (2014). Small-scale aquaponic food production: integrated fish and plant farming. FAO Fisheries and Aquaculture Technical Paper 589, 262. Retrieved December 25, 2014, from http://www.fao.org/3/i4021e/i4021e.pdf.

Timmons, M. B., \& Ebeling, J. M. (2010). Recirculating aquaculture ( $2^{\text {nd }}$ ed.). New York, USA: Cayuga Aqua Ventures.

Tran, T. T. H., Nguyen, T. N. L., Duong, T. Y., \& Nguyen, A. T. (2005). Protein requirements of giant snakehead (Channa micropeltes, Cuvier, 1831) fingerlings. Can Tho University Journal of Science 3, 58-65.

Wortman, S. E. (2015). Crop physiological response to nutrient solution electrical conductivity and $\mathrm{pH}$ in an ebb-and-flow hydroponic system. Scientia Horticulturae 194, 34-42. 